\title{
Enhancing Transformative Social- Emotional Learning with Intergroup Dialogue: An Exploratory Study
}

Annahita Ball ${ }^{\star}$ is an associate professor of social work at the University at Buffalo.

Candra Skrzypek is a doctoral student of social work at the University at Buffalo.

Ball, A., \& Skrzypek, C. (2021). Enhancing transformative social-emotional learning with intergroup dialogue: An exploratory study. Currents, (2)1.

Keywords: mental health, youth mental health, health disparities

Approximately one in six youths have a mental health diagnosis (Whitney \& Peterson, 2019), and many more experience high levels of stress, anxiety, depression, and loneliness (Ghandour et al., 2019; Mojtabai et al., 2016; Twenge et al., 2019). In addition to normative stressors of adolescence, marginalized youth (i.e., racialized youth, youth with disabilities, youth who identify as LGBTQ+, and/or youth with low incomes) experience prejudice, discrimination, and multiple levels of oppression. Instances of bias and hate in schools, including racism, anti-LGBTQ+, antiimmigrant sentiment, antisemitism, and antimuslim incidents, are increasing (Southern Poverty Law Center, 2019).

*annahita@buffalo.edu 
As such, schools are an appropriate target for youth mental health and well-being interventions.

A positive school climate-feelings of safety, social relationships, a sense of belonging, and connectedness in school-has the potential to boost adolescents' mental health (Aldridge \& McChesney, 2018), but youth with marginalized identities are less likely to feel safe and connected at schools (Voigt et al., 2015). Considerable evidence supports preventive interventions that bolster students' mental health (Durlak et al., 2011). Few school-based interventions, however, include issues of power, privilege, or oppression (Barnes, 2019). Transformative social-emotional learning (SEL) (Jagers et al., 2018) uses an equity lens to extend traditional SEL competences (e.g., self-awareness, social awareness, relationship skills) (CASEL, 2020) and include a focus on positive racial identity, understanding of inequity, valuing others' differences and similarities, and relationship building with diverse groups to collaborate toward social justice.

We developed and examined a transformative SEL program using intergroup dialogue (IGD) to develop youths' self- and social awareness related to social identity. Our program is unique because it uses IGD (Dessel et al., 2006) as a modality for school-based transformative SEL. In IGD, diverse individuals engage in facilitated dialogues across cultural differences. IGD at the university level has increased participants' racial-identity awareness (Nagda \& Zúñiga, 2003), perspective taking (Hurtado, 2005), identification of systems of oppression (Madden, 2015), and intergroup empathy (Muller \& Miles, 2017). These outcomes are congruent with transformative SEL competencies; however, little research has explored participants' affective experiences while participating in SEL and IGD and their potential for improving emotional well-being.

Youth with diverse identities from six predominately white high schools engaged in a day of peer-to-peer learning and dialogue. All youth were placed into small groups with youth from different schools, as well as with a trained graduate student facilitator. Youth completed a social justice vocabulary activity to build shared language 
and establish shared expectations and norms focused on relationship building and colearning. Dialogues focused on social identity awareness and cross-cultural empathy and understanding. Youth also identified and dialogued about instances of bias or hate that they witnessed in their schools, followed by an activity where they generated ideas to create change individually and collectively. In the month after the program, we conducted six focus groups with 31 youth participants to explore their perceptions of the program's impact on transformative SEL outcomes. Results revealed that using IGD as a modality for transformative SEL has the potential to improve youths' feelings of belonging, connectedness, empathy, and self-awareness. Youth also expressed their preference and comfort for engaging in dialogues with diverse peers.

Belonging and connectedness emerged as positive outcomes of youths' engagement in the program. They appreciated the opportunity to learn about their peers and recognized that "a lot of people are going through the same stuff." Notably, connectedness was particularly salient for racialized youth who identified feeling isolated in their predominantly white schools and communities. The crossschool event allowed racialized students the opportunity to engage with similar peers across the region. Youth also felt greater empathy while in the program, and that this empathy extended to other aspects of their lives. They recognized that "there's more to the person," noting how issues of privilege and oppression affect their peers differently and that this is not always evident upon first meeting someone. Youth talked about "being mindful" of people's differences and practicing how they might interrupt instances of prejudice and discrimination that they witness at school. Finally, we found that youth reported improved self-awareness, specifically as it relates to their social identities. Participants expressed increased awareness of how their racialized identities, sexuality, religion, and social class interrelate to shape everyday experiences. For example, one youth recognized her growing pride in her identity and unique perspective as a LGBTQ+ Asian American. 
Multiple youth noted that they felt emotional safety and "comfort" while engaging in dialogues with their peers. They shared how their fears of vulnerability and discomfort prevented them from talking about these topics with their friends, but the structure of the crossschool event allowed them to share more because they did not know the other members of their group. One youth commented, "I think just a closed, safe space like that with people you don't really know. I think that is really awesome. And it made me feel more comfortable than if I talk to a group of my closest friends."

Collectively, our results are consistent with research on IGD and early studies of transformative SEL. IGD may be an appropriate and useful modality to achieve transformative SEL outcomes. It is evident that more research should explore the potential of IGD and transformative SEL as an avenue for improving youth well-being, particularly as it relates to belonging, connectedness, empathy, and self-awareness. Our study did not illuminate the underlying interpersonal, cognitive, or affective processes and how they might interrelate to produce outcomes, yet this research is sorely needed in both IGD and SEL literature. Finally, our findings highlight the need for youth engagement in the design of SEL interventions. Youth in this study were more comfortable discussing topics of social identity, privilege, and oppression with peers they did not know. Participatory and emancipatory approaches to transformative SEL have greater potential to improve outcomes and may have greater potential to reach diverse youth.

\section{Biographies}

Annahita Ball's work focuses on educational justice, leveraging schoolfamily-community resources to improve education for all children and youth.

Candra Skrzypek's research interests include educational justice, school climate, and student mental health. 


\section{References}

Aldridge, J. M., \& McChesney, K. (2018). The relationships between school climate and adolescent mental health and wellbeing: A systematic literature review. International Journal of Educational Research, 88, 121145. https://doi.org/10.1016/j.ijer.2018.01.012

Barnes, T. N. (2019). Changing the landscape of social emotional learning in urban schools: What are we currently focusing on and where do we go from here? The Urban Review, 51(4), 599-637. doi.org/10.1007/s11256019-00534-1

CASEL. (2020). CASEL'S SEL framework: What are the core competence areas and where are they promoted? Retrieved from https://casel.org/wpcontent/uploads/2020/12/CASEL-SEL-Framework-11.2020.pdf

Southern Poverty Law Center. (2019). Hate at school. Retrieved from https:// www.splcenter.org/sites/default/files/tt_2019_hate_at_school_report_ final_0.pdf

Dessel, A., Rogge, M. E., \& Garlington, S. B. (2006). Using intergroup dialogue to promote social justice and change. Social work, 51(4), 303-315. https:// doi.org/10.1093/sw/51.4.303

Durlak, J. A., Weissberg, R. P., Dymnicki, A. B., Taylor, R. D., \& Schellinger, K. B. (2011). The impact of enhancing students' social and emotional learning: A meta-analysis of school-based universal interventions. Child development, 82(1), 405-432.

Ghandour, R. M., Sherman, L. J., Vladutiu, C. J., Ali, M. M., Lynch, S. E., Bitsko, R. H., \& Blumberg, S. J. (2019). Prevalence and treatment of depression, anxiety, and conduct problems in US children. Journal of pediatrics, 206, 256-267. https://doi.org/10.1016/j.jpeds.2018.09.021

Hurtado, S. (2005). The next generation of diversity and intergroup relations research. Journal of Social Issues, 61(3), 595-610. https://doi.org/ 10.1111/J.1540-4560.2005.00422.X

Jagers, R. J., Rivas-Drake, D., \& Borowski, T. (2018). Equity \& social and emotional learning: A cultural analysis. CASEL Assessment Work Group Brief Series. Retrieved from https://measuringsel.casel.org/wp-content/ uploads/2018/11/Frameworks-Equity.pdf

Madden, M. (2015). Social class dialogues and the fostering of class consciousness. Equity \& Excellence in Education, 48, 571-588. https://doi: 10.1080/10665684.2015.10 86227

Mojtabai, R., Olfson, M., \& Han, B. (2016). National trends in the prevalence and treatment of depression in adolescents and young adults. Pediatrics, 138(6), e20161878. https://doi.org/10.1542/peds.2016-1878 
Muller, J. T., \& Miles, J. R. (2017). Intergroup dialogue in undergraduate multicultural psychology education: Group climate development and outcomes. Journal of Diversity in Higher Education, 10(1), 52. https://doi: 10.1037/a0040042

Nagda, B. R. A., \& Zúñiga, X. (2003). Fostering meaningful racial engagement through intergroup dialogues. Group Processes \& Intergroup Relations, 6(1), 111-128. https://doi.org/10.1177\%2F1368430203006001015

Twenge, J. M., Spitzberg, B. H., \& Campbell, W. K. (2019). Less in-person social interaction with peers among US adolescents in the 21 st century and links to loneliness. Journal of Social and Personal Relationships, 36(6), 1892-1913. https://doi.org/10.1177\%2F0265407519836170

Voight, A., Hanson, T., O'Malley, M., \& Adekanye, L. (2015). The racial school climate gap: Within-school disparities in students' experiences of safety, support, and connectedness. American Journal of Community Psychology, 56(3-4), 252-267. https://doi.org/10.1007/s10464-015-9751-x

Whitney, D. G., \& Peterson, M. D. (2019). US national and state-level prevalence of mental health disorders and disparities of mental health care use in children. JAMA pediatrics, 173(4), 389-391. https://doi.org/10.1001/ jamapediatrics.2018.5399 